\title{
Fin Efficiency Design of Micro-Channel for Nd: YAG Slab Laser
}

\author{
Rajesh Pant, Jasmeet Kalra, Jagdish Singh Mehta, Pankaj Negi
}

\begin{abstract}
The heat generated by a Slab Lasers can exceed 1,000 watts but the area available for cooling is too small. This results in localization of heat flux which makes heat dissipation a challenge in slab lasers. The Heat transfer coefficient can increase up to a very high range, which can't be efficiently achieved by the conventional water cooling. Micro-channel coolers address this problem competently. These channels contain liquid, which transfers heat to the sink with high efficiency.The objective of this paper is to design the microchannel coolers that will be efficiently capable of removing the heat from the slab laser without causing any thermal distortion in the laser. The dimension of the slab is given as follows:-Length(l) $=50 \mathrm{~mm}$, Width $(w)=8 \mathrm{~mm}$ and thickness $(t)=2 \mathrm{~mm}$.
\end{abstract}

Key Words: MCC, Micro-channel, slab laser, heat sink.

\section{INTRODUCTION}

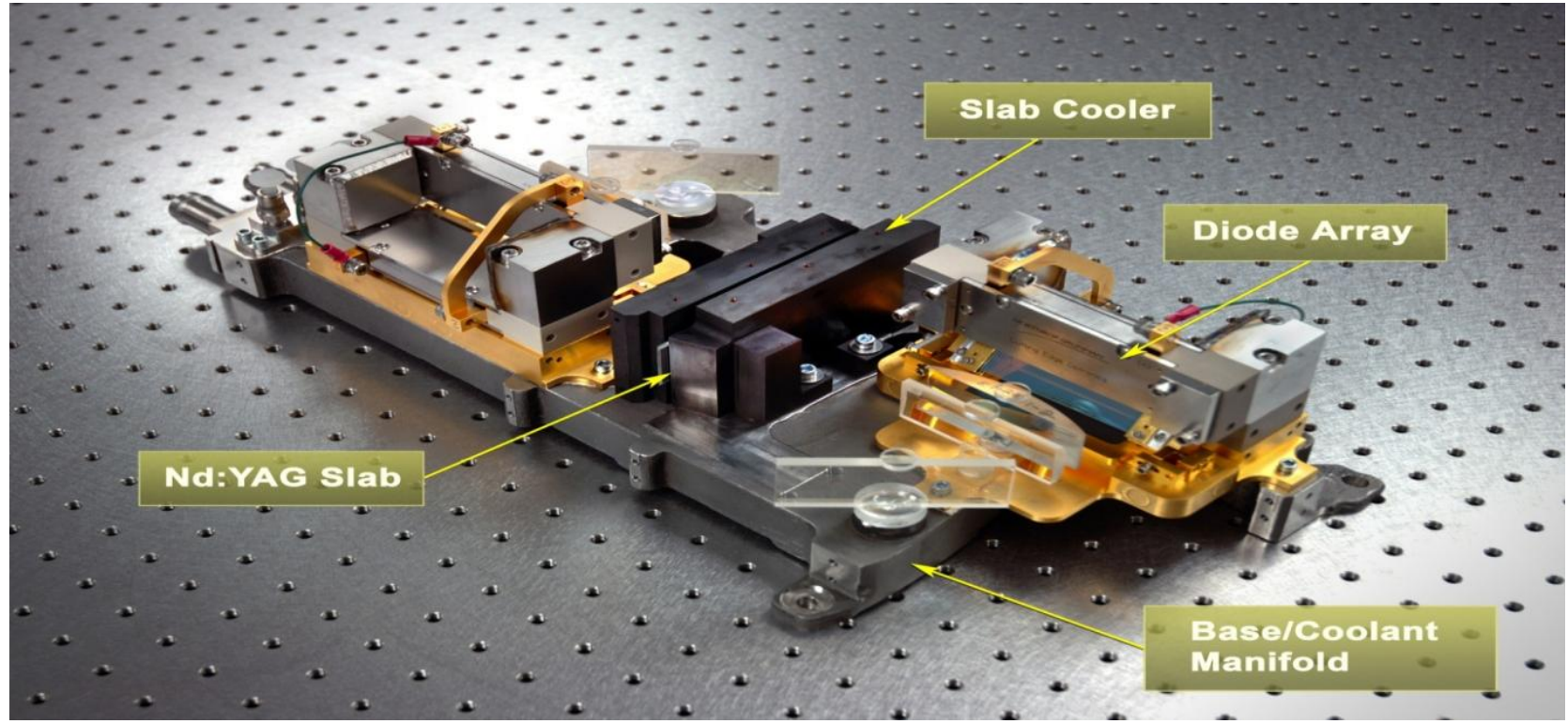

Figure 1 Nd:YAG laser with lid open and with microchannel cooling setup

\section{Nd: YAG SLAB LASERS}

Nd: YAGSlab lasers falls in the category of solid lasers which uses slab form crystal as gain medium.A slab laser has a very less thickness in comparison to other two dimensions. However, some lasers are included in category of slab laser not because they have large aspect ratio but due to their rectangular geometry.

Revised Manuscript Received on September 25, 2019.

Rajesh Pant (Corresponding Author), Assistant Professor, Department of Mechanical Engineering, Graphic Era Hill University, Dehradun, India. E-mail: rajeshpant.mech@ gmail.com;

Jasmeet Kalra, Assistant Professor, Department of Mechanical Engineering, Graphic Era Hill University, Dehradun, India.

Jagdish Singh Mehta, Assistant Professor, Department of Mechanical Engineering, Graphic Era Hill University, Bhimtal, India.

Pankaj Negi, Research Scholar, Department of Mechanical Engineering, Graphic Era University, Dehradun, India.
These lasers use diodes or flash lamps as pumping source. The wavelength of light emitted by Nd:YAGlasers is of $1064 \mathrm{~nm}$.

YAG crystal properties

- Formula: $\mathrm{Y}_{3} \mathrm{~A}_{5} \mathrm{O}_{12}$

- Crystal Structure: Cubic

- Hardness(Moh): 8-8.5

- Melting point: 1970 degree centigrade

Properties of $\mathrm{Nd}$ : $\mathrm{YAG}$ at $25^{\circ} \mathrm{C}$ (with $1 \% \mathrm{Nd}$ doping)

- Formula: $\mathrm{Y}_{2.97} \mathrm{Nd}_{0.03} \mathrm{Al}_{5} \mathrm{O}_{12}$

- Thermal conductivity: $0.14 \mathrm{~W} \cdot \mathrm{cm}-1 \cdot \mathrm{K}-1$

- Specific heat capacity: $0.59 \mathrm{~J} \cdot \mathrm{g}-1 \cdot \mathrm{K}-1$

- Thermal expansion: $6.9 \times 10-6 \mathrm{~K}-1$

- Poisson's ratio: 0.3

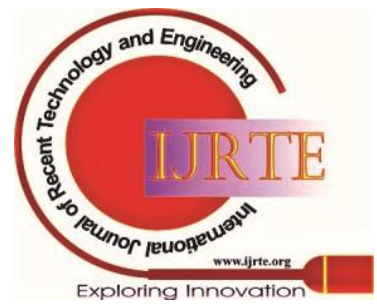




\section{PROBLEM DEFINITION}

A Nd:YAG slab Laser is capable of generating heat of $900 \mathrm{~W}$. The objective is to design the micro-channel coolers that will be efficiently capable of removing the heat from the slab laser without causing any thermal distortion in the laser. The dimension of the slab is given as follows:Length $(\mathrm{l}) \quad=50 \mathrm{~mm}, \quad$ Width $(\mathrm{w}) \quad=8 \mathrm{~mm} \quad$ and thickness $(t)=2 \mathrm{~mm}$. The micro-channels will be placed in contact with the two surfaces of the lasers for the cooling and the other two sides will remain un-cooled.

\section{Assumptions:}

1. There is an only one dimensional heat flow in the slab i.e.In the Y-direction or along the thickness and the other two dimension or sides remain isolated.

2. The Optical axis and the Z-axis of the slab coincide.

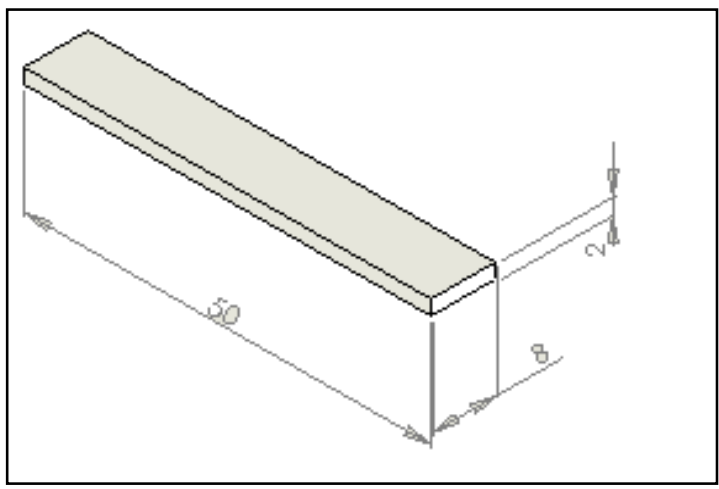

Figure 2 Nd: YAG Slab Geometry

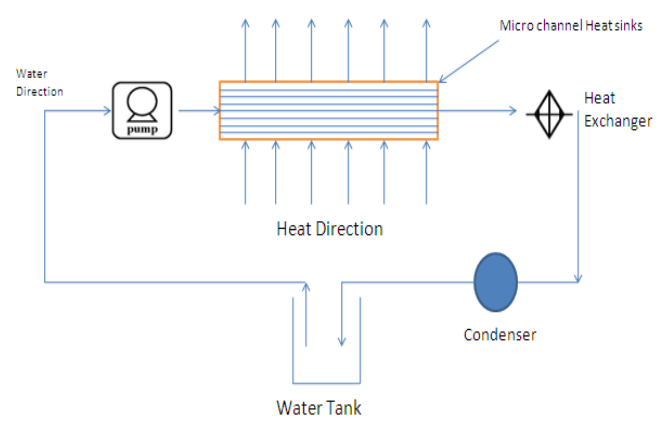

Fig. 3 A simple Diagrammatic representation of Micro-channel

\section{THERMAL ANALYSIS}

The Thermal analysis is done only in the y-direction the temperatures at different section are given by equation (1).

$$
T_{c}-T_{s}=\frac{t^{2}}{8 K} Q
$$

Where Tc=Center temperature of Slab,Ts=Surface temperature of $\mathrm{Slab}, \mathrm{t}=$ thickness of the $\mathrm{slab}, \mathrm{K}=$ Thermal conductivity of Slab,Q=Heat load of slab

$T_{C}-T_{S}=\frac{.002^{2}}{8 * 14 * .008 * .002 * .05} * 900$

$T_{c}-T_{s}=40.17^{\circ} \mathrm{C}$

assuming the uniform distribution of heat from the two upper surfaces. The amount of heat required to be dissipated by the water from one surface is $450 \mathrm{~W}$.

\section{$\mathrm{Q}=\mathrm{hxAx} \Delta T$}

\section{(2)(From one surface)}

Where $\mathrm{h}=$ heat transfer coefficient, $\mathrm{A}=$ area of slab in contact with water, $\Delta T=T_{s}-T_{f}$ and $T_{f}=$ Fluid or Water temperature $=25^{\circ} \mathrm{C}$

\section{$450=h x 0.008 x .05 x(T s-25)$}

Now we have to calculate the value of surface temperature and the heat transfer coefficient. For this we will plot a curve between heat transfer coefficient and the surface temperature and will calculate the surface temperature by varying the heat transfer coefficient.

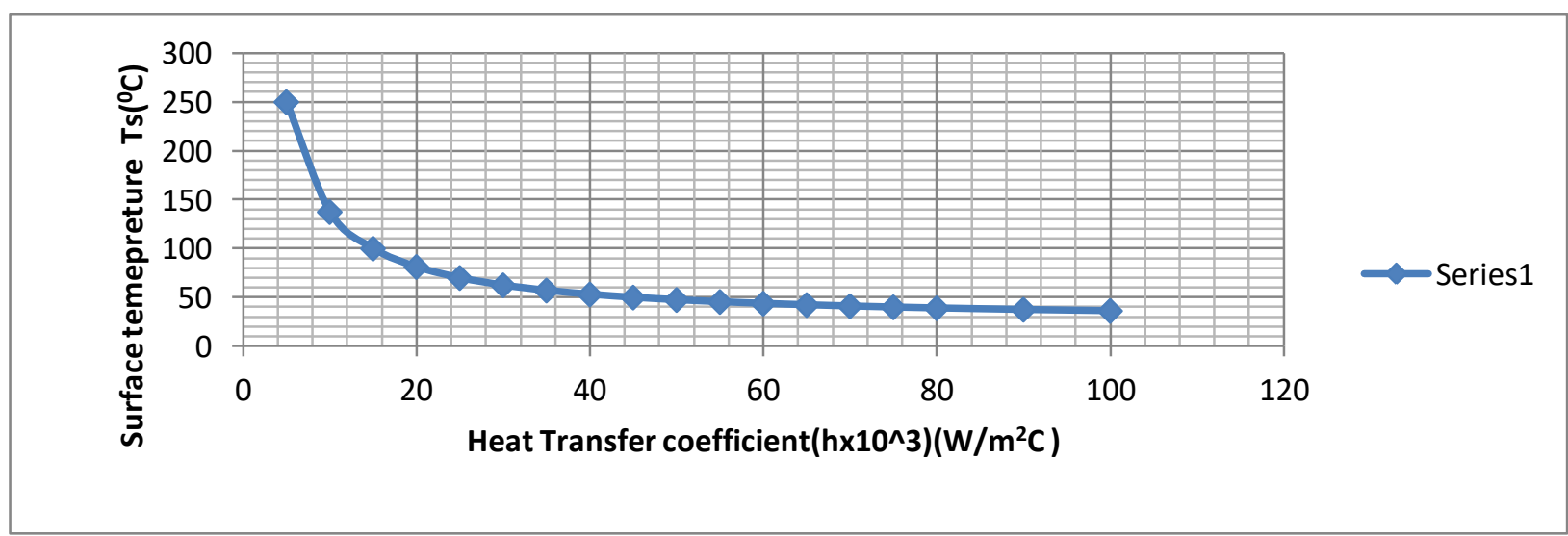

Figure 4 Surface temp. vs heat Transfer coefficient plot

From the above plot let us select the heat transfer coefficient of $30 \times 10^{3} \mathbf{W} / \mathbf{m}^{2} \mathbf{K}$ as our operating value and temperature corresponding to the heat transfer coefficient is $62.5^{\circ} \mathrm{C}$. 
Hence the value of Ts equals to $62.5^{\circ} \mathrm{C}$.

Now substituting the values in equation (1) we get $T_{c}=102.67^{0} \mathrm{C}$.
Now we will check our results with the help of the ANSYS and will perform its thermal analysis.

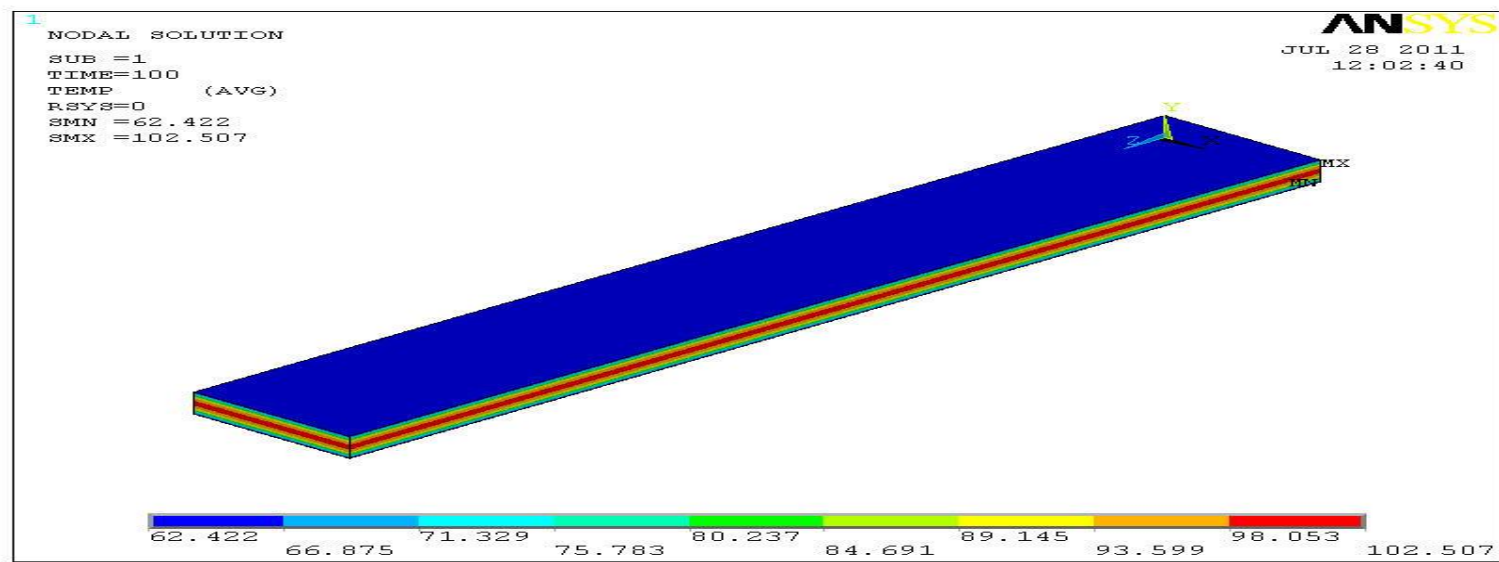

Figure 5 Thermal Analysis of Slab with ANSYS

Modeling Details of the analysis:-

1. Element type - Thermal Mass-Solid brick 8 node 70
2. Hex meshing with sweep

3. Full transient analysis.

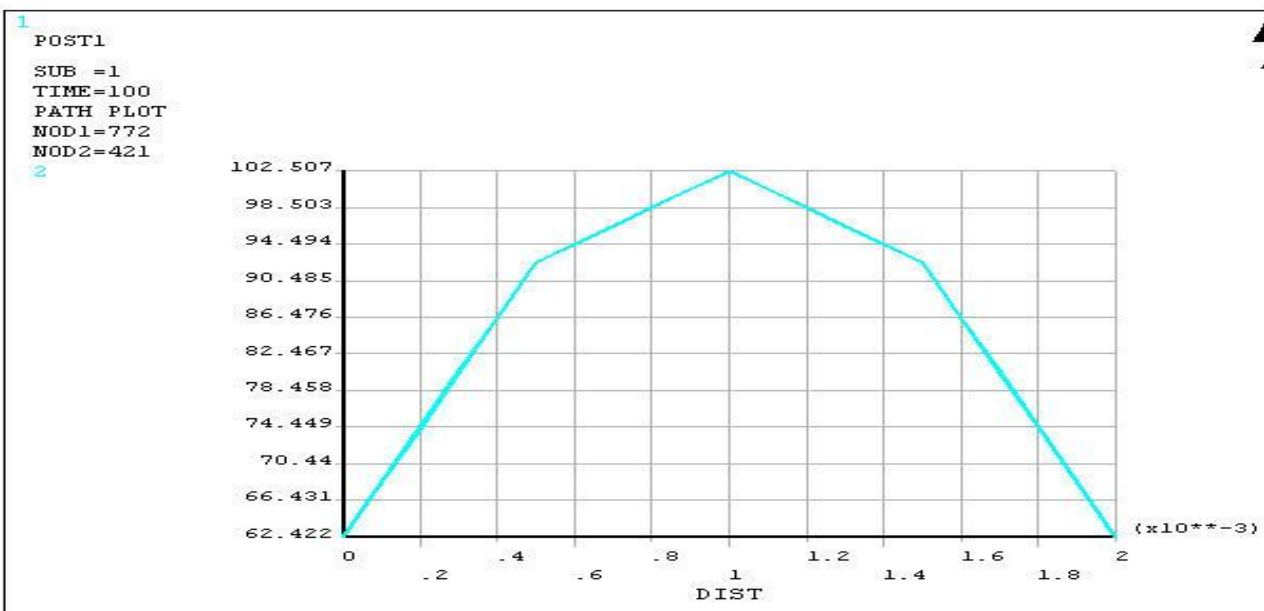

Figure 6 ANSYS Generated Temperature distribution curve in Laser Slab

As we can see that our mathematical results of center temperature of the micro-channel slab agrees with the ANSYS generated temperature distribution curve.

\section{CALCULATION OF FIN EFFICIENCY}

The fin efficiency of micro-channels is:-

$$
\eta=\frac{\tanh N}{N}
$$

Where

$$
\mathrm{N}=\left(2 \mathrm{~h} / \mathrm{k}_{\mathrm{w}} \mathrm{W}_{\mathrm{w}}\right)^{1 / 2} \mathrm{z}
$$

$\mathrm{h}=$ heat transfer coefficient $=31200 \mathrm{~W} / \mathrm{m}^{2} \mathrm{C}$, Thermal conductivity $(\mathrm{Kw})=398 \mathrm{~W} / \mathrm{mC}$, Fin width $(\mathrm{Ww})=100 \mu \mathrm{m}$, channel $\operatorname{depth}(\mathrm{z})=600 \mu \mathrm{m}$.

Putting all the values in the equation (4):-

$$
\mathrm{N}=\left(\frac{2 * 31200}{398 * 100 * 10^{-06}}\right)^{0.5} * 600 * 10^{-06}
$$

$\mathrm{N}=0.781$.

Substituting the value of $\mathrm{N}$ in the equation (3):-

$$
\begin{aligned}
& \eta=\frac{\tanh (0.781)}{0.781} \\
& \eta=\frac{0.653}{0.781}=0.8361
\end{aligned}
$$

Hence the fin efficiency of the channel comes to be $\mathbf{8 3 . 6 1 \%}$

\section{RESULTS AND DISCUSSION}

Following are the results obtained from the calculation of the micro-channel heat sinks:

A micro-channel having the configuration Length(l) $=50 \mathrm{~mm}$,

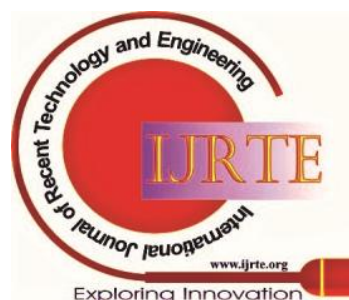


Width $(\mathrm{w})=8 \mathrm{~mm}$, thickness $(\mathrm{t})=2 \mathrm{~mm}$, h=heat transfer coefficient $=31200 \mathrm{~W} / \mathrm{m}^{2} \mathrm{C}$, Thermal conductivity $(\mathrm{Kw})=398 \mathrm{~W} / \mathrm{mC}$, Fin width $(\mathrm{Ww})=100 \mu \mathrm{m}$ and channel $\operatorname{depth}(\mathrm{z})=600 \mu \mathrm{mcan}$ easily dissipateheat up to $900 \mathrm{~W}$ with an efficiency of $83.61 \%$ which is far better than the conventional method. This problem has been solved mathematically and our results agree with the ANSYS generated curve of temperature distribution.

The above study and calculation of Micro-channel coolers proved that the micro-channels are the advance and the better way of cooling the lasers than the other conventional methods. From the above study it can also be concluded that 1) In micro-channel heat sink design the convective heat transfer coefficient play significant role and conductiveheat transfer coefficienthas negligible effect on heat dissipation. Hence the main focus should be on internal design of micro channel for better performance.

2) Fluid flow and thermal performance can be optimized by improving the geometry of micro channel design and finding balance between pressure drop and heat transfer constraints.

Result obtained helped in concluding that the temperature generated in the thin slab lasers is quite high and needs to be removed by an efficient cooling method, it has also been seen that the heat spreaders having high conductivity proves to be a better. Lastly these results proved that the microchannels are smartly able to dissipate the heat generated inside the lasers through convection.

\section{REFERENCE}

1. Walter Koencher, Solid state laser engineering.

2. D.B. Tuckerman and RF.W. Pease, "OptimizedConvectiveCooling Using Micromachined Structures," ElectrochemicalSoc. Extended Abstracts 82.197 (1982).

3. Qu, W., and Mudawar, I. Measurement and correlation of critical heat flux in two-phase microchannel heat sink. Int. J. Heat Mass Transfer 47 (2004), 2045-2059.

4. Oh, C. H., and Englert, A. B. Critical heat flux for low flow boiling in vertical uniformly heated thin rectangular channels. Int. J. Heat Mass Transfer 36 (1993), 325-335.

5. Lienhart-V, J. H., and Lienhart-IV, J. H. A heat transfer text book, third ed. Phlogistonpress,2008.

6. Katto, Y. Critical heat flux. Int. J. Multiphase Flow 20 (1994), 53-90.

7. White, F. M. Fluid Mechanics, fourth ed. McGraw-Hill, 1999.

8. Zhang, W., Hibiki, T., Mishima, K., and Mi, Y. Correlation of critical heat flux for flowboiling of water in mini-channels. Int. J. Heat Mass Transfer 49 (2006), 1058-1072.

9. Richard J. Phillips Micro-channel heat sink Lincoln laboratory journal volume 1 number 1 (1988), 31-48. 